\title{
Concept of Correlation between Active Learning and Employability Skills in TVET
}

\section{Reyanhealme Rohanai ${ }^{1}$, Hasyamuddin Othman ${ }^{1 *}$, Khairul Azhar Mat Daud ${ }^{2}$, Nurul Huda Omar ${ }^{3}$, Maimunah Ahmad ${ }^{1}$, Mohd Erfy Ismail ${ }^{1}$, Abdullah Sulaiman $^{4}$}

\author{
${ }^{1}$ Faculty of Technical and Vocational Education, \\ Universiti Tun Hussein Onn Malaysia, Batu Pahat, 86400, MALAYSIA \\ ${ }^{2}$ Faculty of Technology Creative and Heritage, \\ Universiti Malaysia Kelantan, Bachok, 16300, MALAYSIA \\ ${ }^{3}$ SMK Munshi Sulaiman, \\ Jalan Kluang, Taman Megah, Batu Pahat, 83000, MALAYSIA \\ ${ }^{4}$ Institute Ahli Sunnah Wal Jamaah, \\ Universiti Tun Hussein Onn Malaysia, Batu Pahat, 86400, MALAYSIA
}

\section{*Corresponding Author}

DOI: https://doi.org/10.30880/ojtp.2020.05.01.003

Received $10^{\text {th }}$ December 2019; Accepted 28 ${ }^{\text {th }}$ February 2020; Available online $31^{\text {th }}$ March 2020

\begin{abstract}
An Industrial Revolution 4.0 promoted by Malaysian government entitles the rapid growth of manufacturing sector thus promotes a multi-level of workforce and skilled workforce needed to satisfy the rapid technological development application. The challenges arise on preparing the individuals to meet with the current business and the students need to be prepared in such way satisfied the business expectations. Looking into this situation, this paper aims to study the concept of correlation between active learning and employability skills in Technical and Vocational Education and Training (TVET). The study assumes that there is positive relationship between employability skills and active learning in improving student's quality. The method of study involves documentation analysis on previous research to prove the importance of employability skills enhancing student's quality and the effectiveness of active learning; Problem-Based Learning (PBL) method in preparing the students to meet the expectations. The main findings of this study claimed that there was a positive relationship between employability skills and PBL method. Result acknowledge that PBL has the solutions to help students develop employability skills and behavior. As all ideas and suggestion in this paper was cited as the understanding from previous study findings and arise from the reviews of expertise. The recommendation on future study is crucial to justify deeply the effectiveness of this correlational concept by performing experimental study to provide a concrete evidence towards this understanding.
\end{abstract}

Keywords: TVET, employability skills, active learning, Problem-based Learning 


\section{Introduction}

Malaysia is now on their end-point journey towards Vision 2020 and is now ready in transforming to become a developed nation during the second phase of fifteen-year period. Every single thing that now serve the world nation has changed tremendously in terms of technological development and urged the rapid growth in manufacturing sector. As the consequences, a multi-level of workforce and skilled work force needed to satisfy this rapid technological development application. This change has created impacts on the nature of work where a high level of use technology is a necessity to compete in the global arena (Jailani et al., 2015) The challenges arise as a more flexible workforce with advanced technical skills coupled with well-developed generic skills such as creative thinking, problem solving and analytical skills, is greatly needed by the employer in industry in order to meet the current business challenges. A recent study on the mismatch skills performed by data from by Idham et al. (2017) found that the result of the study agrees that job mismatch and English proficiency and employability skills influenced unemployment among graduates. According to annual report made by Bank Negara Malaysia in 2017, it proves that the factors underlying high youth and graduate unemployment comes from labour market mismatches arising from both limited high-skilled job creation and inadequate supply of industry-ready graduates. Therefore, employability skills play an important role to helps in creating a better job security and without employability skills there will be a decline in competitiveness and diminishing in economic return (Bakar et al., 2013).The initiative on educational institution should highlight the needs of the industry and students by creating awareness and guiding the students in self-analysis and in acquisition of skills (Kaushal, 2016).

\subsection{Research Purpose}

This paper aims to study the concept of correlation between active learning and employability skills in TVET. Perhaps, this research could enrich the information on enhancing employability skills among TVET graduates and proves clarification on the suitability of using PBL method as a teaching medium to improvise employability skills.

\subsection{Research Assumption}

This study assumes that there is positive relationship between employability skills and active learning in improving student's quality. This indicates assumption that the employability skills among TVET graduates can be improved through the application of Problem Based Learning as a teaching medium.

\section{Methodology}

The main methodology in this research focus mainly in the critical review on previous research findings regarding to the topics of employability skills and active learning concept (PBL). A systematic method of searching on potential materials to be selected has been performed by the researcher. A good methodology should address review protocol, source of information and modes of study selection as potential methods in constructing a good review paper (Gülpınar \& Güçlü, 2013). Hence, this paper covers the proper method on review protocol of systematic search that covers potential keywords used in study scope as such employability skills and problem-based learning. Moreover, a numerous database also has been used as a main platform to extract potential information towards the recent study of PBL application in empowering employability skills. It was cited that a review on literature through available numerous database shall be conducted as it has been systematically 'searched' to ease the process of paper selection (Wee \& Banister, 2015). Those databases involved in this study was gathered from various reliable online scholar platform as such Elsevier, Scopus, Web of Science and as well as Google Scholar. The issues to be addressed were related to the study of employability skills including the importance of the skills and the potential skills needed by the students as cited by the previous research. Apart from that, the effectiveness of PBL method in teaching method also being discussed further and the reflection towards its contribution to improves employability skills are determined. Across of all these methodologies, all the works cited from potential past literature are then being analyzed and summarized to reflect the purpose of this study. 


\section{Reviews on Literature}

\subsection{The importance of employability skills in TVET}

Employability in TVET plays a significant impact in preparing individual to perform well in the job. In other words, employability skill is a group of important skills instilled in each individual in order to produce productive workforce. The importance of employability skills in TVET has shown its continuous significant contribution in preparing the student with adequate working skills and strong personal quality. As in earlier of 1964, a study by Becker defines the importance of employability skills. He stated that education and training raise productivity of workers by imparting them with useful knowledge and skills that increase their lifetime earnings and profits of the enterprise. In addition to, employability skills make TVET graduates to gain employment and make them successful in their occupations (Lees, 2002). Regression result by International Labor Organization (ILO) claimed that the impact of TVET on employment was strong and the increments of TVET cause the increments of employment in developing economies.

Employability skills also have been chosen as a most favorable aspect needed by the employers. It acts as a performance indicator for employers in hiring new employee. In employers' perspectives, employability skills of the students will help the employer to combat challenges faced by the company and effectively helps in resolving all or any problems encountered. Previous study proves that employers rated the importance of employability skills at a high level (Husain et al., 2010). As such, skills in problem-solving, tool handling competency, presentation skills and team working skills feature highly amongst the employers as important skills demanded from the students (Md Saad \& Ab. Majid, 2014). Ultimately, employers want graduates that able to help them in dealing with changes, and skillful in solving matters related to technical or non-technical problems and able to work independently. The challenges now rely on the understanding of students towards the world of work and the awareness on business making is desirable. Therefore, enhancing the employability skills requires a holistic approach in refining the needs of employability skills among the graduates and the participation of real industry experience in active learning concept must be justified.

\subsection{Problem-Based Learning Concept}

PBL used to provide a learning environment to integrate the development of these skills and behaviours into curriculum in a holistic way and utilize the diversity of student experiences to develop problem-solving skills, improve intrinsic motivation and quality of learning. PBL was developed in response to the problems and limitations of traditional teaching approaches. It is an encouraging way to learn, as students work with problems that are challenging and observed in their real life. Students realize that the learning needed to solve and understand existing problems is valuable (Barrows, 2002).

PBL method has been widely used in medical study as student will experience an active learning towards the real problem-solving situation. Among the effectiveness of this PBL method was literally been justified from previous study by Alrahlah (2016) clearly supports the effectiveness of PBL in dental education. Through PBL, students learn to become associates in the teaching and learning processes; they take responsibility for their learning, successfully work as part of a team, cope with new and changing circumstances, and acquire lifelong learning skills. Although there are different models of PBL has been used by past researcher, they commonly share the following characteristics:

- Learning starts with problem, question, or scenario to be investigated. The problem is typically interdisciplinary, related to the real world and ill defined. This is however promoting investigation on a number of solution and selection on final solution must be defined with fairly reasonable. The key point in PBL is that problem is introduced before the students know how to solve it. Hence, solving the problems will be the element to drives the learning.

- Students are then will work in a small team, self-directed teams with a facilitator. The facilitator can be dedicated to one team or between numbers of team depending on the coaching needs. Facilitators can be selected among the students or any faculty members. Students need to identify the learning issues, work individually and then share the knowledge or results as to teach each other. After that, the team will work together in collectively applies the cumulative knowledge to solve the problems. The level of problems can be last from one session or even in longer periods (throughout semester) depending on the subject requirement.

- $\quad$ PBL claimed to produce independent learners, and allows students to create their own understanding towards their own motivation and passion. It introduces students to realize that the learning needed to solve and understand existing problems is valuable. Similar to study of PBL in TEVT, the findings of study suggest that PBL has a positive impact on students' learning, technical and social competencies in the TVET (Mohamad, 2017). 


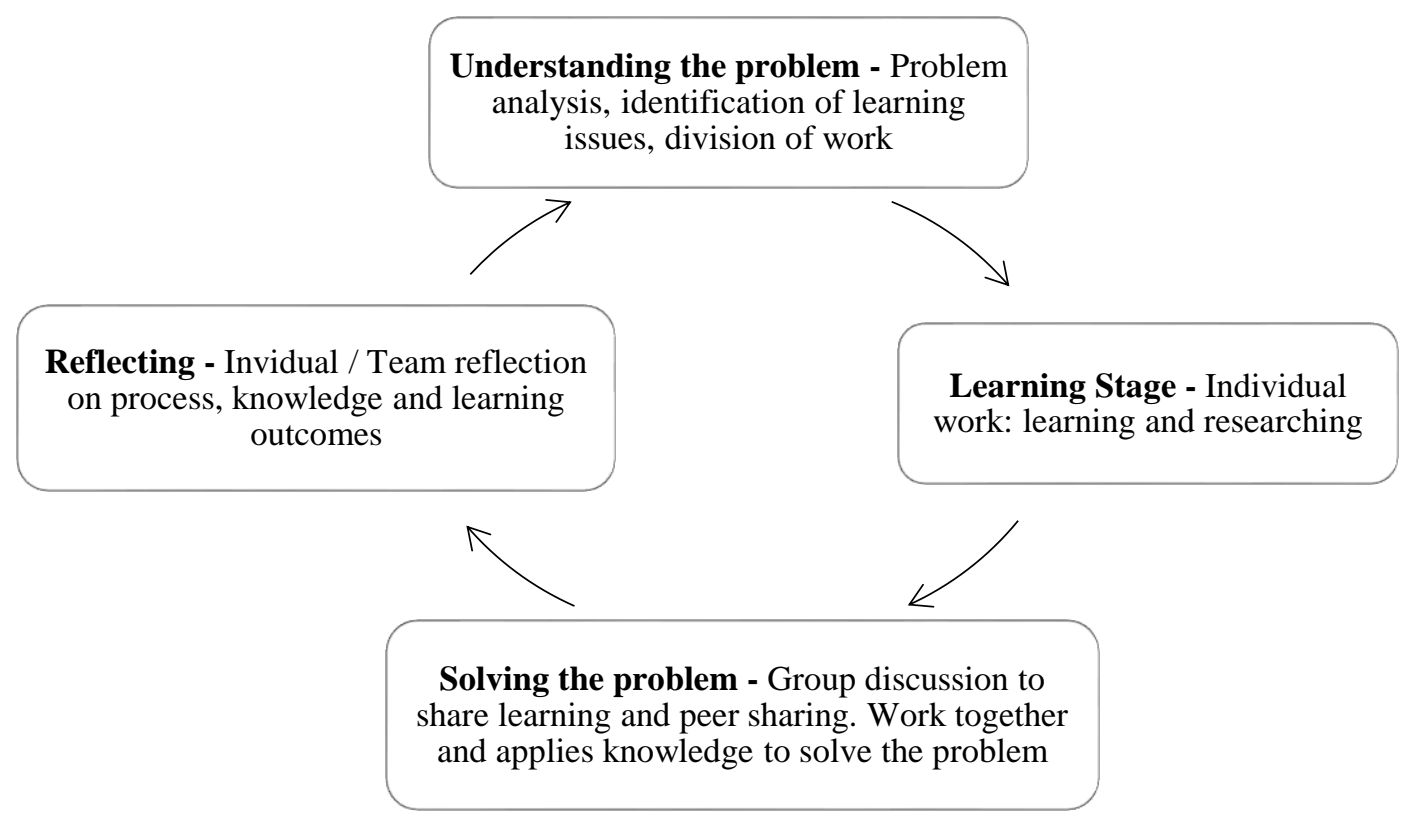

Fig. 1 - The PBL learning cycle

The effectiveness of PBL shows a significant impact in evidence clearly supports the effectiveness on assessing students on medical field and in TVET as well. Through PBL, students learn to become associates in the teaching and learning processes and able to develop the skills they require whilst at university and on into employment (Rosen, 2012). In TVET itself, PBL has a positive impact on students' learning, technical and social competencies in the TVET and the students were pretty much aware of PBL and its benefits towards learning (Mohamad, 2017).

\section{Findings}

\subsection{The real insight of PBL and employability skills}

There is close alignment between the characteristic of good PBL and employability skills assessment. The relationship can be well defined through the real understanding on the concept of employability skills and PBL teaching method. The assessment of PBL is challenging for the students as they are given autonomy to set learning goals that may or may not meet the tutor's expectations. PBL is questioning about problem and designed to be messy, ill-defined and interdisciplinary and derived from the real-world situations. One difficulty in evaluating PBL is that the process used to solve a problem and the solution reached are equally important. The students might easily immediately jump onto their own conclusion when making a decision. This is however can be controlled if the effects of the complexity in assessing PBL method is clarified further. The common effects of PBL method:

1. Social interactions - social interactions in a PBL group are complex as they unfold in sequence over time. Acquisition of collaboration skills during PBL is somehow may be vary depending to the student interest throughout the learning process. For instance, an understanding of effective teaching is necessary and the roles of facilitators could harmonize the group participation. The facilitators understanding must incorporate the skills and practices of effective teaching and the ways in which teaching is practiced shall overlapping with various contexts (Devlin \& Samarawickrema, 2010). As a result, students will naturally develop their skills in communication and enhancing their team work skills.

2. Creativity and Innovation - In PBL there is no such way to solve solution at certain fixed answer or standard solution. The answer will be verified in accordance to the creativity of students to explain their solution. The guidance from facilitators must be placed in such way that the student understanding to be developed in the correct way of learning but not too direct them with real answer. Let the student to think wisely through the possible explanation on tools or resources to be taken when they answering the question. This could expose the 
students to sharpen their critical thinking and at the same time teach them to assess and answer the question in creative way.

3. Control - The pace of control should focus on student's self-development. Over period of time students will develop their confidence and will aware about their own strengths and weaknesses. The success factors will totally depend on the efforts and commitment that they show throughout the learning process takes place. For instance, this self-development helps to reduce the dependency on tutors / supervision and could gradually enhance self-reliance in performing job with less supervision.

4. Development of a wider perspectives - Since problems are devised to be quite general and messy thus it promotes investigation in a number of areas and elements such as business awareness and ethics can easily be promoted by the choice of problem.

5. Content learned is relevant to professional situations - This situation could affect to complexity and confusion in finding the solution. This is however can be solved by formulating the suitable curriculum that match with potential professional situations that best match with student's expectation. Educators should filter out unnecessary curriculum assessment. The curriculum shall meet the current demanding skills so that the survivability of students can be updated over the time.

Employability skills related much with teamwork and others skills needed to adapt with real working situation. Generally, employability skills comprise the combination of skills of work readiness, personal qualities and work-related skills. There were studies on the framework of employability performed by past researchers in order to highlight the best formulation to design an adequate employability skill for TVET graduates. Unfortunately, employers keep continue to cite significant skill gaps among new recruits. According to Rahmah et al. (2011), found that graduates are found to be lacking in employability skills, and have low performance in the work place. Zaharim et al. (2008) study found that required employability skills for fresh graduate engineer and engineer to be employed and successful are communication skills, problem solving and interpersonal skills. Most studies found in literature, showed that the highest ranking of employability skills from an employer's perspective was communication skills (Azian \& Mun, 2011; Rahmah et al., 2011). Recently, Bank Negara Malaysia (2016) reported that a survey conducted by the World Bank and Talent Corporation 10 found that $90 \%$ of companies believe that university graduates should have more industrial training by the time they graduate, and $81 \%$ of companies surveyed rated communication skills as a major deficit among graduates. Similar study also found by Azian and Mun (2011) where a survey conducted by the Malaysian Employers Federation showed that $68 \%$ of employers rated communication skills as being the most demanded skill in job application. It was also found that work experience, interpersonal skills, leadership and commitment are among the skills that also has been voted. Recent study also has shown that communication, thinking and problem-solving skills are indeed an important need for college vocational graduates 'employment in industries (Haron, et.al., 2019). For instance, Zaharim et al (2009) has literally summarize the list of skills for Malaysian Graduates and categorize employability as personal attributes, personal skills and TVET knowledge.

The correlation between employability skills and PBL teaching method lies on the agreement on preparing the good qualities of employability skills among TVET students through PBL curriculum assessment. As employability skills much related to teamwork and communication skills, PBL is the most suitable teaching method to enhance those skills as it introduces active self-learning concept and nurture group motivation. PBL focuses explicitly on these aspects and provides a very suitable medium for developing the following skills and behaviors:

1. Communication - verbal, written, sharing knowledge to others, writing reports and delivering presentations. Thus, it enhances communication skills effectively.

2. Respect and Self-reliance - Students learnt in accepting and commenting ideas or perceptions in positive way and critically evaluating contributions in making decision. The good interpersonal skills could be resulted as student able to learn on accepting and criticizing others idea in positive insight.

3. Problem solving - The effective problem solving can be produced as student learn on how to think creatively in planning for solution and decide critically method in solving the problems. The explicitly taught continually developed all over the learning time. This could enhance students' capabilities in making a good decision

4. Leadership - In PBL, students will work as a team and a leader will leads the group towards achieving the group goals. Hence, it practically exposed the students to be a leader and polishing the students to be a goal-oriented person and good team players. 
A study by Beaumont \& Frank (2003) also supported the above statement and literally measured the effectiveness of PBL teaching method in enhancing student employability skills. Thus, the concept of correlation will rely on the agreement among these both factors: the required skills on employability skills and the effectiveness from implementing PBL method.

\subsection{The concept of correlation between employability skills and PBL teaching method}

Upon the agreement and vital understanding towards the importance of employability skills and the contribution of PBL within education performance as mentioned above, the concept of correlation upon past literature review now can be conceptualized. The integration of employability skills within the process of PBL provide a suitable medium for the incorporation of employability skills development among the TVET graduates. At the same time, it directly helps the educational institution to understand the needs of the industry and students by creating awareness and guiding the students in self-analysis and in acquisition of skills. The selection upon potential Malaysian TVET employability skills are being summarized from the subset comparison made by local researcher and definitions from the international accreditation bodies such as UK Core Skills, US Workplace Know How (SCAN) and Canada Employability Skills Profile (Common Wealth of Australia, 2002).

Table 1- The concept of correlation between employability skills and PBL teaching method

\begin{tabular}{|c|c|c|c|}
\hline Theme & $\begin{array}{c}\text { Potential } \\
\text { Malaysian TVET } \\
\text { Employability } \\
\text { Skills } \\
\end{array}$ & Expected Skills Outcome & PBL Teaching Method \\
\hline \multirow{2}{*}{$\begin{array}{l}\text { Interpersonal } \\
\text { Skills }\end{array}$} & $\begin{array}{l}\text { Communication } \\
\text { Skills }\end{array}$ & $\begin{array}{l}\text { Listen, speaks, writes and } \\
\text { negotiate effectively }\end{array}$ & $\begin{array}{l}\text { PBL train students to explain } \\
\text { knowledge among each other, } \\
\text { defending findings and challenging } \\
\text { others with critical evaluation on } \\
\text { findings }\end{array}$ \\
\hline & Teamwork Skills & $\begin{array}{l}\text { Works well among peers } \\
\text { with high sensitivity and } \\
\text { respect each other }\end{array}$ & $\begin{array}{l}\text { Teamwork is facilitated from } \\
\text { coaching and commitment to solve } \\
\text { experienced issues among team } \\
\text { members }\end{array}$ \\
\hline \multirow{3}{*}{$\begin{array}{l}\text { Workplace } \\
\text { Skills }\end{array}$} & $\begin{array}{l}\text { Basic Technical } \\
\text { Knowledge }\end{array}$ & $\begin{array}{l}\text { Understand the basic } \\
\text { knowledge on related } \\
\text { technical subject }\end{array}$ & $\begin{array}{l}\text { Formulation on question that } \\
\text { relevant to practitioners in the } \\
\text { discipline }\end{array}$ \\
\hline & Technology & $\begin{array}{l}\text { Able to use related } \\
\text { technology and update } \\
\text { technology skills }\end{array}$ & $\begin{array}{l}\text { Apply updated technology in the } \\
\text { formulating question if possible }\end{array}$ \\
\hline & Business Awareness & Aware on business goals & $\begin{array}{l}\text { Problem can be designed multi- } \\
\text { disciplinary involving business } \\
\text { awareness aspect }\end{array}$ \\
\hline \multirow{2}{*}{$\begin{array}{l}\text { Initiative and } \\
\text { enterprises } \\
\text { skills }\end{array}$} & $\begin{array}{l}\text { Problem Solving } \\
\text { Skills }\end{array}$ & $\begin{array}{l}\text { Think critically and } \\
\text { develop creative solutions }\end{array}$ & $\begin{array}{l}\text { Structure problem solving; students } \\
\text { are practiced to solve real-world } \\
\text { problem structurally }\end{array}$ \\
\hline & $\begin{array}{l}\text { Innovative and } \\
\text { enterprise }\end{array}$ & $\begin{array}{l}\text { Adaptable and develop } \\
\text { strategic vision }\end{array}$ & $\begin{array}{l}\text { Messy problem can have number of } \\
\text { possible solutions and hence } \\
\text { encourages innovation }\end{array}$ \\
\hline \multirow{3}{*}{ Learning skills } & $\begin{array}{l}\text { Management skills } \\
\text { (planning / } \\
\text { organizing) }\end{array}$ & $\begin{array}{l}\text { Good in self-management } \\
\text { and efficient in making } \\
\text { decision and utilize } \\
\text { resources }\end{array}$ & $\begin{array}{l}\text { Students engaged with the } \\
\text { development of team and understand } \\
\text { team maturity over active learning }\end{array}$ \\
\hline & Self- awareness & $\begin{array}{l}\text { Good ownership } \\
\text { determination }\end{array}$ & $\begin{array}{l}\text { Each student will hold specific roles } \\
\text { in solving the solution and hence } \\
\text { increase awareness on completing } \\
\text { the task independently }\end{array}$ \\
\hline & Learning & $\begin{array}{l}\text { Has passion for active and } \\
\text { ongoing learning }\end{array}$ & $\begin{array}{l}\text { The team commitment encouraging } \\
\text { motivation and self-belief }\end{array}$ \\
\hline
\end{tabular}


The table above shows the contribution of PBL learning in enhancing employability skills. It explains the concept of correlation between potential Malaysian TVET Employability Skills and PBL teaching method. These findings reflect the similarities with past literature review mentioned that PBL is the best ingredients in enhancing individual's quality for a long-term knowledge retention, performance or skill-based assessment (Yew \& Goh, 2016). PBL therefore appears to be a superior and effective strategy to train competent and skilled practitioners and to promote long-term retention of knowledge and skills acquired during the learning experience (Strobel \& Barneveld, 2009). Others past literature that withdrawn common findings towards this conceptual correlation is an empirical study made by Aidoo et.al. (2016) showing that the student's problem-solving skills and thinking abilities had improved when the PBL instructional method was used in teaching strategy (Aidoo et.al., 2016). Furthermore, PBL helps to create students' process skills, thinking abilities and as well as nurture positive attitude towards learning of subject matters. Even though PBL could affect greater challenges for teachers to prepare for dynamic teaching plans, teachers will slowly get familiar by experience with whole process of PBL and evidence proved that students' learning motivation was improved and increased the learning outcomes (Chung, Yeh, \& Chen, 2016). Similarly, a recent study by Charoensakulchai, Kantiwong, \& Piyaraj (2019) also indicates that a successful implementation of problem-based learning able to nurture a good attitude development among students especially attitudes towards group work. In vice versa, study also revealed that a positive teamwork attitude confirms the effectiveness of PBL implementation. Hence, as TVET is main education sector that imparts with preparing skillful nations, PBL was a recommended right teaching delivery method that able to enrich the quality of education towards providing skilled practitioners in the future.

\section{Conclusion and Recommendations}

As a conclusion, it was believed that PBL has the ingredients to develop a good employability skills and personal behaviors development. Through PBL, students learn to become associates in the teaching and learning processes as they take responsibility for their learning, successfully work as part of a team, cope with new and changing circumstances, and acquire lifelong learning skills. It was believed that the concept of PBL teaching method that centered on students or students active learning, with learning style setting on actual condition at work location would totally have implication on existence of employability skills development of students. In practicing PBL in any educational institution, it would suggest that the educational institution should understand the needs of the industry and students by creating awareness and guiding the students in self-analysis and in acquisition of skills.

Therefore, this concept paper can argue that PBL is effective in enhancing employability but we are not yet in a position towards providing a concrete evidence that the benefits are achieved. All the cited ideas and suggestion in this paper were collected as the understanding from previous study and gathering reviews from the expertise. Our main concern now is to share our opinions and explains clearly the positive relationship of using PBL method and its beneficial towards enhancing the TVET employability skills. This could open up the future opportunity of study on empowering our TVET employability skills through PBL teaching method. The recommendation on future study could justify deeply the effectiveness of this correlational concept by performing experimental study to provide a concrete evidence towards this understanding.

\section{Acknowledgement}

We are thankful to research assistant, respondents and all quarters who have contributed to the research.

\section{References}

Aidoo, B., Boateng, S. K., Kissi, P. S., \& Ofori, I. (2016). Effect of Problem-Based learning on Students' Achievement in Chemistry. Journal of Education and Practice.

Alrahlah, A. (2016). How effective the problem-based learning (PBL) in dental education. A critical review. The Saudi Dental Journal, 155-161.

Azian, H., \& Mun, L. (2011, April 10). English Work: top jobs only for those who know the language well. The Star.

Bakar, A. R., Mohamed, S., \& Hamzah, R. (2013). An Assessment of Workplace Skills Acquired by Students of Vocational and Technical Education Institutions. International Education Studies, 6, 11.

Barrows, H. (2002). Is it truly possible to have such a thing as dPBL? 
Beaumont, C., \& Frank, B. (2003). Enhancing Employability through Problem-based Learning. Delivering Employability Conference.

Charoensakulchai, S., Kantiwong, A., \& Piyaraj, P. (2019). Factors Influencing Problem-Based Learning: Students' and Teachers' Perspectives. AMEE Journal.

Chung, P., Yeh, R. C., \& Chen, Y.-C. (2016). Influence of problem-based learning strategy on enhancing student's industrial oriented competences learned: an action research on learning weblog analysis. International Journal of Technology and Design Education, 285-307.

Common Wealth of Australia. (2002). Employability Skills for Small and Medium Size Enterprises: Common Wealth of Australia.

Devlin, M., \& Samarawickrema, G. (2010). The Criteria of Effective Teaching in a changing higher education context. Higher Education Res. Develop., 111-124.

Gülpınar, Ö., \& Güçlü, A. (2013). How to write a review article? Turkish Journal of Urology, 44-48. doi:10.5152/tud.2013.054

Haron, M., Hussain, M. M., Zulkifli, R. M., Mat Nashir, I., \& Ma'arof, N. I. (2019). Employability Skills Needed by Vocational College Graduates: Feedback from Industries. Journal of Technical Education and Training, 86-94.

Husain, M. Y., Mokhtar, S. B., Ahmad, A. A., \& Mustapha, R. (2010). Importance of Employability Skills from Employers' Perspective. International Conference on Learner Diversity 2010, 430-438.

Jailani, Wan Mohd Rashid, Noraini, \& Wahid. (2005). Technical and Vocational Education and Training (TVET) from Malaysia Perspective. International TT-TVET EU-Asia-Link Project Meeting, VEDC Malang.

Kaushal, U. (2016). Empowering Engineering Students Through Employability Skills. Higher Learning Research Communications, 6, 4.

Lees, D. (2002). Graduate Employability. Retrieved from General Centre Website: http://www.gla.ac.uk/employability/documents/litrev.rtf

Md Saad, M. S., \& Ab. Majid, I. (2014). Employers' perceptions of important employability skills required from Malaysian engineering and information and communication technology (ICT) graduates. Global Journal of Engineering Education, 16, 110-115.

Mohamad, H. B. (2017). The Impact of Problem-Based Learning on Students' Competencies in Technical Vocational Education and Training. Aalborg Universitetsforlag.

Rahmah, I., Ishak, Y., \& Wei Sieng, L. (2011). Employers' Perception on graduates in Malaysia service sector. International Business Management, 5, 184-193.

Rosen, C. (2012). A Problem Based Approach to Teaching Employability and Independent Learning Skills. The Higher Education Academy (STEM).

Strobel, J., \& Barneveld, A. v. (2009). When is PBL more effective? A meta-synthesis of meta-analyses comparing PBL to conventional classrooms. Interdisciplinary Journal Problem-based Learning.

Wee, B. V., \& Banister, D. (2015). How to Write a Literature Review Paper? Transport Reviews, 36, $278-288$.

Yew, E., \& Goh, K. (2016). Problem-Based Learning: An Overview of its Process and Impacton Learning. Health Professions Education, 75-79.

Zaharim, A., Yusof, Y., Mohamed, A., Omar, M., Muhammad, N., \& Mustapha. (2009). Practical Framework of Employability Skills for Engineering Graduate in Malaysia. International Conference on Engineering Education Rodos, Greece, 921-927.

Zaharim, A., Yusoff, Y. M., \& Omar, M. (2008). Engineering Employability skills required by Employers in Asia . Proceedings of the 6th WSEAS International Conference on Engineering Education. 